\title{
RADIOLOGICAL AND CLINICAL EVALUATION OF LONG-STANDING DIABETIC PATIENTS FOR LIMB ISCHAEMIA AND ABDOMINAL VESSEL INVOLVEMENTS (SMA) AT NKP SALVE INSTITUTE OF MEDICAL SCIENCES, NAGPUR
}

\author{
S. D. Deshmukh1, R. Sonarkar², Sushrut M. Fulare ${ }^{3}$, N. Chandak $^{4}$ \\ ${ }^{1}$ Associate Professor, Department of General Surgery, NKP Salve Institute of Medical Sciences, Nagpur. \\ ${ }^{2}$ Assistant Professor, Department of General Surgery, NKP Salve Institute of Medical Sciences, Nagpur. \\ ${ }^{3}$ Associate Professor, Department of General Surgery, NKP Salve Institute of Medical Sciences, Nagpur. \\ ${ }_{4}^{4}$ Senior Resident, Department of General Surgery, NKP Salve Institute of Medical Sciences, Nagpur.
}

\begin{abstract}
BACKGROUND

Peripheral arterial disease refers to the obstruction or deterioration of arteries other than those supplying the heart and within the brain. There are a number of pathologic processes like diabetes that manifests their effects on the arterial circulation. Chronic mesenteric ischaemia is a medical condition connected with stenosis of the mesenteric arteries and inadequate blood supply to the small intestine wall. In our study, we are evaluating the patients of long-standing diabetes mellitus for limb ischaemia/ gangrene and mesenteric artery stenosis and ischaemia.

The purpose of this study is to determine the prevalence of asymptomatic abdominal vessel stenosis in long-standing diabetic patients presenting with chronic limb ischaemia and diabetic foot ulcer.
\end{abstract}

\section{MATERIALS AND METHODS}

In this descriptive study, 68 diabetic patients with CLI and ulcer and/or gangrene of the foot admitted in our hospital came for treatment between June 2013 and December 2014. All patients were subjected to arterial colour Doppler of lower limb and abdominal vessels.

\section{RESULTS}

On Doppler examination, 48 patients out of 68 (71\%) had normal vessel diameter. 15 patients (22\%) had reduction in the diameter of the vessel upto $3 \mathrm{~mm}$ and 5 patients (7\%) had significant reduction in diameter for more than $3 \mathrm{~mm}$.

\section{CONCLUSION}

Hence, this study recommends the screening of abdominal vessels for early detection of abdominal vessel stenosis in long-standing diabetic patients.

\section{KEYWORDS}

Diabetes Mellitus, Lower Limb Peripheral Arterial Disease (PAD), Chronic Mesenteric Ischaemia.

HOW TO CITE THIS ARTICLE: Deshmukh SD, Sonarkar R, Fulare SM, et al. Radiological and clinical evaluation of long-standing diabetic patients for limb ischaemia and abdominal vessel involvements (SMA) at NKP Salve Institute of Medical Sciences, Nagpur. J. Evolution Med. Dent. Sci. 2018;7(08):1030-1033, DOI: 10.14260/jemds/2018/235

\section{BACKGROUND \\ Lower limb peripheral arterial disease (PAD) is a common} complication of diabetes mellitus. ${ }^{1}$ As compared to normal subjects, PAD prevalence is significantly higher in diabetic patients $^{2}$ and is associated with more severe clinical manifestations and a higher risk of critical limb ischaemia (CLI) and limb loss. ${ }^{3}$ The majority of non-traumatic major amputations are performed in diabetic subjects. ${ }^{4}$ Chronic limb ischaemia is strongly associated with cardiovascular risk factors such as cigarette smoking, diabetes mellitus, dyslipidaemia, hypertension and hyperhomocysteinaemia. Chronic mesenteric ischaemia is a medical condition connected with stenosis of the mesenteric arteries and inadequate blood supply to the small intestine wall. The main cause of this condition is atherosclerosis. Other less frequent

'Financial or Other Competing Interest': None.

Submission 11-01-2018, Peer Review 03-01-2018,

Acceptance 10-02-2018, Published 19-02-2018.

Corresponding Author:

Dr. Sushrut M. Fulare,

Plot No. 236, Surendra Nagar,

Nagpur, Maharashtra.

E-mail:drsmfulare@gmail.com

DOI: $10.14260 /$ jemds $/ 2018 / 235$

\section{(c) $($ i) $\odot$}

causes are fibromuscular dysplasia, Buerger disease, periarteritis nodosa and aortic aneurysm. It is considered that symptoms of chronic mesenteric ischaemia occur if two of the three major intestinal vessels are stenotic or occluded. Most patients have symptoms of atherosclerotic changes in other vessels, especially the coronary arteries. A study conducted by Hansen et al revealed that asymptomatic celiac axis or superior mesenteric artery stenosis can be identified at duplex ultrasonography in over $17 \%$ of the elderly. Most patients have isolated celiac trunk stenosis. Such a high percentage of asymptomatic patients with stenosis of the mesenteric arteries can be connected with possible development of collateral circulation through anastomoses between the mesenteric arteries and celiac trunk. ${ }^{5}$ In this study, we have included 68 patients of either gender who were diabetic for more than 15 years and admitted for peripheral vascular disease and infection of lower limb.

\footnotetext{
Aims and Objectives

To study the patients of Diabetes Mellitus type II with peripheral vascular disease/ gangrene for mesenteric artery stenosis/ ischaemia of 10 years or more duration of diabetes mellitus.
} 


\section{MATERIALS AND METHODS}

This descriptive study population include 68 consecutive diabetic patients with CLI and ulcer and/or gangrene of the foot who were admitted in our hospital for treatment between June 2013 and December 2014. It was a longitudinal study. The sample size was calculated based on the medical record section data of previous year. In all patients, the presence of diabetes mellitus was defined as the use of hypoglycaemic drugs (either insulin and/or oral agents). All patients had critical limb ischaemia (CLI) according to TASC criteria ${ }^{6}$ with non-healing ( $>4$ weeks of local dressing and conservative treatment) ulcer and/or gangrene of the foot. All the patients were subjected to routine haematological and biochemical investigations including complete blood count, kidney function, blood sugar level, HBA1C, HIV and HBsAg. All patients were subjected to arterial colour Doppler of lower limb and abdomen. Patients are evaluated for superior mesenteric artery ischaemia with colour Doppler ultrasound. It has sensitivity of $80 \%$ if done by experienced person in morning time with $2.5 \mathrm{MHz}$ convex probe. B mode assesses the anatomy of segment, while Doppler assesses the blood flow. Peak systolic and diastolic velocity is best assessed at $<60^{\circ}$ angle ${ }^{7}$ study by convenient sampling technique. Since the duration of the study was less, the patients were selected by convenience sampling technique.

The celiac trunk and superior mesenteric artery have different blood flow morphologies: PSV is higher in the superior mesenteric artery than in the celiac tripod and EDV is higher in the celiac trunk than in the superior mesenteric artery. The criteria applied in the diagnosis of mesenteric artery stenosis are taken from various studies on Doppler US evaluation of stenosis of the superior mesenteric artery and celiac trunk. PSV $>275 \mathrm{~cm} / \mathrm{s}$ at the level of the superior mesenteric artery identifies stenosis $>70 \%$ (sensitivity $92 \%$, specificity $96 \%$, positive predictive value $80 \%$ and negative predictive value 99\%). PSV $>200 \mathrm{~cm} / \mathrm{s}$ at the level of the celiac trunk identifies stenosis > 70\% (sensitivity 87\%, specificity $80 \%$, positive predictive value $63 \%$ and negative predictive value 94\%).8 Diameter of the abdominal vessels were calculated in all patients and compared with the normal values; that which were found less than the normal were considered to be stenotic vessel.

\begin{tabular}{|c|c|c|c|}
\hline $\begin{array}{c}\text { Doppler } \\
\text { Parameters }\end{array}$ & Celiac Trunk & SMA & IMA \\
\hline PSV & $90-190$ & $80-200$ & $90-140$ \\
\hline EDV & $30-65$ & - & $0-10$ \\
\hline RI & - & $0.8-0.85$ & $>0.9$ \\
\hline PI & $1.5 \pm 0.02$ & $2.6-4.8$ & $>3.5$ \\
\hline D & $0.78 \pm 0.08$ & $0.8 \pm 0.07$ & $0.4 \pm 0.03$ \\
\hline BF & - & $380-640$ & $80-130$ \\
\hline Table 1. Normal Values of Mesenteric Arterial Blood Flow \\
\multicolumn{4}{|r}{}
\end{tabular}

PSV: Peak systolic velocity $(\mathrm{cm} / \mathrm{s})$; EDV: End diastolic velocity (cm/s); RI: Resistive index; PI: Pulsatility index; D: Diameter (cm); BF: Arterial blood flow (mL/min)

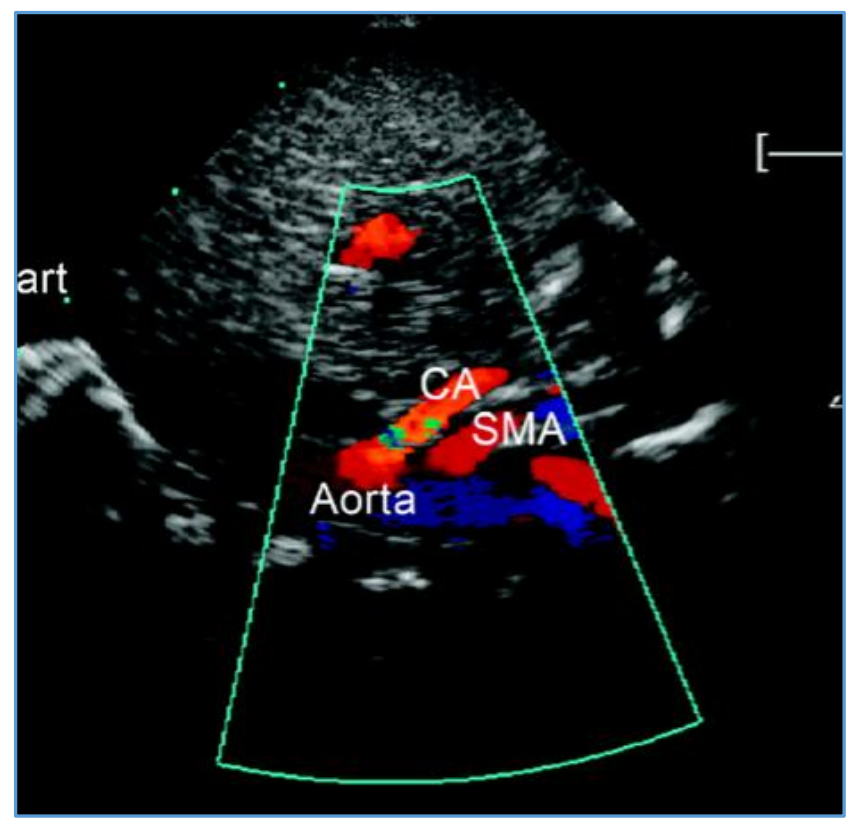

\section{Doppler Flow Velocimetry in Superior Mesenteric Artery}

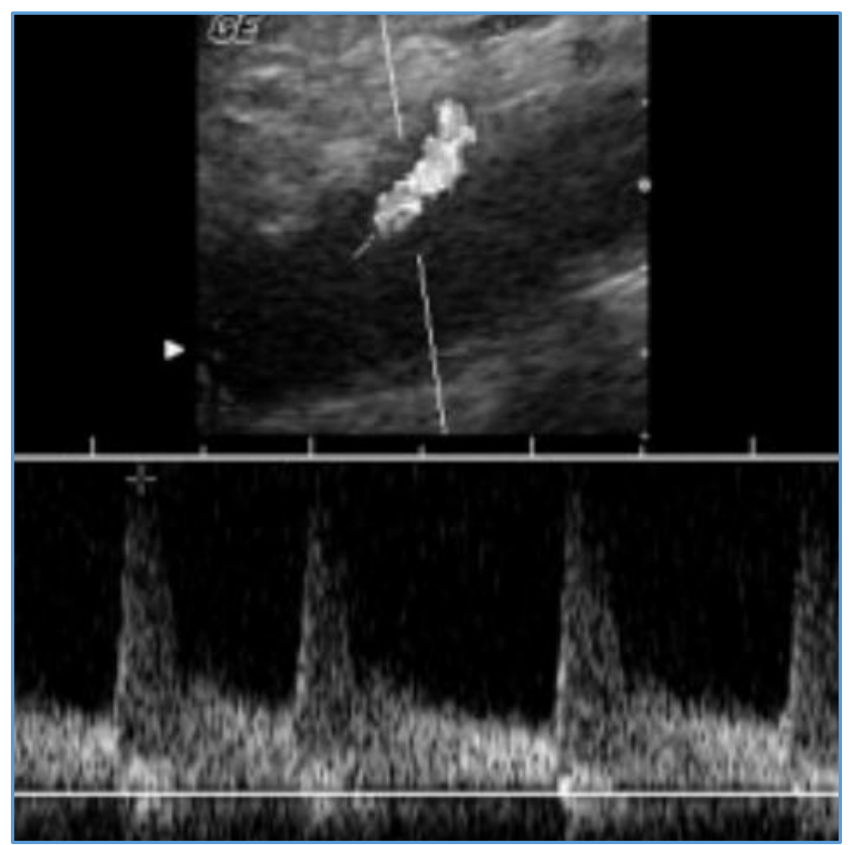

Colour Doppler showing Stenosis in SMA

\section{Inclusion Criteria}

Patients of type II diabetes mellitus with peripheral vascular disease of more than 10 years duration, who have consented to be a part of the study.

\section{Statistical Analysis}

Demographic and clinical presentation was presented as descriptive statistics in forms of tables and charts with mean standard deviation and range. Analytical statistics using Pearson's chi-square test was used for analysis of categorical variables. 


\section{RESULTS}

\section{Gender}

A total of 68 patients were enrolled in this study, of which 40 were males and 28 were females. Male-to-female ratio was 1.4 (males were affected more than females). Study by convenient sampling technique, since the duration of the study was less. The patients were selected by convenient sampling technique.

\begin{tabular}{|c|c|c|}
\hline Male & Female & Total \\
\hline 40 & 28 & 68 \\
\hline \multicolumn{2}{|c|}{ Table 2. Gender Wise Distribution } \\
\hline
\end{tabular}

\section{Age}

Maximum patients, 27 were found to be in the age group of 51 - 60 years.

\begin{tabular}{|c|c|c|}
\hline Age & Patients & $\mathbf{\%}$ \\
\hline$<50$ years & 15 & $22 \%$ \\
\hline $51-60$ years & 27 & $40 \%$ \\
\hline $61-70$ years & 20 & $30 \%$ \\
\hline$>70$ years & 6 & $8 \%$ \\
\hline Total & $\mathbf{6 8}$ & $\mathbf{1 0 0} \%$ \\
\hline \multicolumn{2}{|c|}{ Table 3. Age Wise Distribution } \\
\hline
\end{tabular}

\section{Duration of Diabetes}

Maximum patients were found to be suffering from diabetes between 16 and 20 years.

\begin{tabular}{|c|c|c|}
\hline Duration & No. of Patients & $\mathbf{\%}$ \\
\hline 15 years & 12 & $18 \%$ \\
\hline 16- 20 years & 31 & $45 \%$ \\
\hline 21-25 years & 25 & $37 \%$ \\
\hline Total & $\mathbf{6 8}$ & $\mathbf{1 0 0 \%}$ \\
\hline Table 4. Distribution according to Duration of Diabetes \\
\hline
\end{tabular}

\section{Diameter of Abdominal Vessels}

On Doppler study, 48 patients out of $68(71 \%)$ had normal vessel diameter. 15 patients $(22 \%)$ had reduction in the diameter of the vessel upto $3 \mathrm{~mm}$ and 5 patients (7\%) had significant reduction in diameter for more than $3 \mathrm{~mm}$.

\begin{tabular}{|c|c|c|c|c|}
\hline \multirow{2}{*}{$\begin{array}{c}\text { Duration } \\
\text { of DM }\end{array}$} & \multicolumn{3}{|c|}{$\begin{array}{c}\text { No. of Patients with Vessel Wall } \\
\text { Stenosis }\end{array}$} & \multirow{2}{*}{ Total } \\
\cline { 2 - 4 } & $\begin{array}{c}\text { Normal } \\
\text { Diameter }\end{array}$ & $\mathbf{1}$ - $\mathbf{3} \mathbf{~ m m}$ & $\begin{array}{c}\text { More Than } \\
\mathbf{3} \mathbf{~ m m}\end{array}$ & \\
\hline 15 years & 10 & 2 & - & 12 \\
\hline 16- 20 years & 26 & 3 & 2 & 31 \\
\hline $21-25$ years & 12 & 10 & 3 & 25 \\
\hline Total & $\mathbf{4 8}$ & $\mathbf{1 5}$ & $\mathbf{5}$ & $\mathbf{6 8}$ \\
\hline \% & $\mathbf{7 1 \%}$ & $\mathbf{2 2 \%}$ & $\mathbf{7 \%}$ & $\mathbf{1 0 0 \%}$ \\
\hline \multicolumn{4}{|c|}{ Table 5. Comparison between Duration of DM } \\
and Vessel Stenosis \\
\hline
\end{tabular}

\begin{tabular}{|c|c|c|c|}
\hline $\begin{array}{c}\text { Duration of } \\
\text { DM }\end{array}$ & $\begin{array}{c}\text { Normal } \\
\text { Diameter of } \\
\text { Vessel Wall }\end{array}$ & $\begin{array}{c}\text { Abnormal } \\
\text { Diameter of } \\
\text { Vessel Wall }\end{array}$ & P value \\
\hline$<20$ years & 36 & 12 & \multirow{2}{*}{0.001827} \\
\hline$>20$ years & 12 & 13 & \\
\hline \multicolumn{3}{|c|}{ Table 6. Applying Chi-Square Test to compare } \\
Duration and Vessel Stenosis \\
\hline
\end{tabular}

\section{DISCUSSION}

The aetiology of chronic mesenteric ischaemia is often multifactorial. The most common cause is atherosclerosis involving the proximal portions of the celiac, superior mesenteric or inferior mesenteric artery. ${ }^{9}$

Both type-1 and type-2 diabetes are powerful and independent risk factors for coronary artery disease, stroke and peripheral arterial disease.10,11 Accelerated atherosclerosis as well as microvascular disease are the major vascular complications of diabetes, constituting the main cause of morbidity and mortality in this common metabolic disorder. The primary causal factor leading to the pathophysiologic alterations in the diabetic vasculature is the chronic exposure to high levels of blood glucose. ${ }^{12} \mathrm{~A}$ causal relationship between chronic hyperglycaemia and diabetic microvascular disease, long inferred from a variety of animal and clinical studies ${ }^{13}$ has been definitely established by data from the Diabetes Control and Complications Trial comprising two multicentre, randomised, prospective controlled clinical studies. ${ }^{12,14}$ A relationship between chronic hyperglycaemia and diabetic macrovascular disease in patients is also supported by a number of other reports. ${ }^{15,16}$

Although, the effects of glucose in adversely modulating cellular properties occur by a variety of mechanisms, ${ }^{17,18}$ the most important pathway involved in the pathogenesis of the accelerated atherosclerosis in diabetes is most likely the increase in non-enzymatic glycation of proteins and lipids with irreversible formation and deposition of reactive advanced glycation end products (AGEs). This review specifically focuses on proposed mechanisms by which AGEs accumulate in the extracellular space and within cells of the vessel wall and thus contribute to the accelerated atherosclerosis in diabetes.

The normal circulation to the bowel includes blood supply from the celiac artery, the superior mesenteric artery and the inferior mesenteric artery. There is, however, the potential for collateralisation between the vascular territories of these vessels. ${ }^{19}$ The abundant mesenteric blood supply and slow progression of atherosclerosis allows these collateral pathways to develop. ${ }^{20}$ Because of this collateral circulation within the mesenteric vasculature, patients may not experience symptoms until two or three major mesenteric vessels are involved.

Chronic symptoms are caused by the gradual decrease in blood flow to the intestines. Because total blood flow to the intestine can vary from $25 \%$ when fasting to $35 \%$ after eating; symptoms are more prevalent after eating. ${ }^{21}$

The purpose of this study is to determine the prevalence of asymptomatic abdominal vessel stenosis in long-standing diabetic patients presenting with chronic limb ischaemia and diabetic foot ulcer. In this study, on Doppler examination 48 patients out of $68(71 \%)$ had normal vessel diameter. 15 patients $(22 \%)$ had reduction in the diameter of the vessel upto $3 \mathrm{~mm}$ and 5 patients (7\%) had significant reduction in diameter for more than $3 \mathrm{~mm}$. The patients with duration of diabetes more than 20 years had significant reduction in diameter of vessel wall, i.e. vessel wall stenosis when comparison and analysis was done using Pearson's chisquare test. 


\section{Limitation of the Study}

Due to short duration of the study, convenience sampling technique was followed. Thus, sampling size was also calculated by convenience. The results of the study cannot be generalised due to the potential bias resulting from the sampling technique and sample size estimation.

\section{CONCLUSION}

The purpose of our study was to show the long-standing diabetes mellitus patient with peripheral vascular disease should be screened for macrovascular involvement of abdominal vessels, i.e. abdominal aorta, celiac trunk, superior mesenteric artery and inferior mesenteric artery. Here as the stenosis was not significant, i.e. more than $70 \%$, the patients did not have abdominal symptoms, probably because of the collateral circulation within the mesenteric vasculature.

Hence, this study recommends the screening of abdominal vessels for early detection of abdominal vessel stenosis in long-standing diabetic patients.

\section{REFERENCES}

[1] Tapp RJ, Balkau B, Shaw JE, et al. Association of glucose metabolism, smoking and cardiovascular risk factors with incident peripheral arterial disease: the DESIR study. Atherosclerosis 2006. (In press).

[2] Lee AJ, Macgregor AS, Hau CM, et al. The role of haematological factors in diabetic peripheral arterial disease: the Edinburgh artery study. Br J Haematol 1999;105(3):648-54.

[3] Jude EB, Oyibo SO, Chalmers N, et al. Peripheral arterial disease in diabetic and nondiabetic patients: a comparison of severity and outcome. Diabetes Care 2001;24(8):1433-7.

[4] Carmona GA, Hoffmeyer P, Hermann FR, et al. Major lower limb amputations in the elderly observed over ten years: the role of diabetes and peripheral arterial disease. Diabete Metab 2005;31(5):449-54.

[5] Song SY, Chung JW, Kwon JW, et al. Collateral Pathways in Patients with Celiac Axis Stenosis: Angiographic-Spiral CT Correlation. RadioGraphics 2002;22(4):881-93.

[6] Dormandy JA, Rutherford RB. Management of peripheral arterial disease (PAD). TASC Working Group. TransAtlantic Inter-Society Consensus (TASC). J Vasc Surg 2000;31(1 Pt 2):S1-S296.

[7] Genovese EA, Fonio P, Floridi C, et al. Abdominal vascular emergencies: US and CT assessment. Critical Ultrasound Journal 2013;5(Suppl 1):S10.

[8] Mitchell EL, Moneta GL. Mesenteric duplex scanning. Perspect Vasc Surg Endovasc Ther 2006;18(2):175-83.
[9] Sreenarasimhaiah J. Chronic mesenteric ischemia. Best Pract Res Clin Gastroenterol 2005;19(2):283-95.

[10] Schwartz CJ, Valente AJ, Sprague EA, et al. Pathogenesis of the atherosclerotic lesion. Implications for diabetes mellitus. Diabetes Care 1992;15(9):1156-67.

[11] Stamler J, Vaccaro O, Neaton JD, et al. Diabetes, other risk factors, and 12-yr cardiovascular mortality for men screened in the Multiple Risk Factor Intervention Trial. Diabetes Care 1993;16(2):434-44.

[12] The Diabetes Control and Complications Trial Research Group. The effect of intensive treatment of diabetes on the development and progression of longterm complications in insulin-dependent diabetes mellitus. N Engl J Med 1993;329:977-86.

[13] Nathan D. Relationship between metabolic control and long term complications of diabetes. In: Kahn CR, Weir GC. eds. Joslin's diabetes mellitus. Philadelphia: Lea \& Febiger 1994: p. 620-31.

[14] The Diabetes Control and Complications Trial/Epidemiology of Diabetes Interventions and Complications Research Group, Lachin JM, Genuth S, et al. Retinopathy and nephropathy in patients with type 1 diabetes four years after a trial of intensive therapy. N Engl J Med 2000;342(6):381-9.

[15] Kuusisto J, Mykkanen L, Pyorala K, et al. Non-insulindependent diabetes and its metabolic control are important predictors of stroke in elderly subjects. Stroke 1994;25(6):1157-64.

[16] Colwell JA. Multifactorial aspects of the treatment of the type II diabetic patient. Metabolism 1997;46(12 Suppl 1):1-4.

[17] King GL, Shiba T, Oliver J, et al. Cellular and molecular abnormalities in the vascular endothelium of diabetes mellitus. Annu Rev Med 1994;45:179-88.

[18] Koya D, King GL. Protein kinase C activation and the development of diabetic complications. Diabetes 1998;47(6):859-66.

[19] Cleveland TJ, Nawaz S, Gaines PA. Mesenteric arterial ischaemia: diagnosis and therapeutic options. Vasc Med 2002;7(4):311-21.

[20] Biebl M, Oldenburg WA, Paz-Fumagalli R, et al. Surgical and interventional visceral revascularization for the treatment of chronic mesenteric ischemia-when to prefer which? World J Surg 2007;31(3):562-8.

[21] Chang RW, Chang JB, Longo WE. Update in management of mesenteric ischemia. World J Gastroenterol 2006;12(20):3243-7. 